\title{
Prediction of Body Image Dissatisfaction from Self-esteem, Thin-ideal Internalization and Appearance-related Social Comparison
}

\author{
Shima Shahyad ${ }^{1,{ }^{*}}$, Shahla Pakdaman ${ }^{1}$, Omid Shokri ${ }^{1}$ \\ 1. Department of Psychology, Shahid Beheshti University, Tehran, Iran
}

*Corresponding Author: Shima Shahyad, Ph.D Student, Department of Psychology, Shahid Beheshti University, Tehran, Iran Email: shima.shahyad@gmail.com

\begin{abstract}
Introduction: The present study has aimed to demonstrate the relationship between body image dissatisfaction and three variables of self-esteem as a psychological factor along with thin-ideal internalization and appearance-related social comparison as psychosocial factors.

Methods: To conduct this study, 477 Tehran high-school students were recruited by a cluster sampling method. Afterwards, they filled out the Rosenberg Self-esteem Scale, Appearance Evaluation Subscale, Physical Appearance Comparison Scale as well as Sociocultural Attitudes towards Appearance Questionnaire-4. Finally, the collected data were analyzed using the Pearson' correlation coefficient together with the stepwise regression.

Results: Findings were indicative of a direct correlation between body image dissatisfaction and variables of thin-ideal internalization as well as appearance-related social comparisons. Meanwhile, there was a negative correlation between self-esteem and body image dissatisfaction. In addition, self-esteem could better work in assessing body image dissatisfaction. Because, it explains 19\% of the variance thereof.

Conclusion: According to the results, it can be concluded that self-esteem plays a central role in predicting body image dissatisfaction. Therefore, health professionals should place a value on such a role while using preventive measures or interventions.
\end{abstract}

Keywords: Dissatisfaction at Body, Thin-ideal Internalization, Appearance-related Social Comparison, Self-esteem

Article History: Received: 2 Jul 2015; Revised: 25 Sep 2015; Accepted: 19 Oct 2015

Cite this article as: Shahyad S, Pakdaman S, Shokri O. Prediction of body image dissatisfaction from self-esteem, thin-ideal in-ternalization and appearance-related social comparison. Int J Travel Med Glob Health. 2015; 3 (2):65-9.

\section{Introduction}

Body image is the representation of the personal feeling about one's outer appearance which encompasses physical and perceptual dimensions [1]. The key elements in body image include evaluation (body dissatisfaction), investment (referring to the importance that individuals place on their physical appearance) and emotions [2]. Appearance constitutes an important part of the individual's identity and in social situations is the first characteristic that comes into view. Studies also show that body image and attractiveness have greater importance for women and adolescents than other sections of a society [3]. Over the last past decades, a thin body has been promoted as the standard of beauty and success in both developed and developing countries. Failure to reach an ideal body characterized as being long and thin, results in body image dissatisfaction among young women and adolescents [4].

Body image dissatisfaction is recognized as negative thoughts and feelings about the weight and body shape [5]. Body image dissatisfaction could bring about physical and psychological problems [6]. There are also researches which link body image dissatisfaction with smoking, drinking [7], obsession and social anxiety [8], sensitivity in interpersonal communications, obsessive-compulsive behavior [9] and eating disorders [10]. Given the wide range of problems that originate from body image dissatisfaction, scholars turned their attention towards identifying the factors which give rise to women's body image dissatisfaction. A number of studies suggest that there is a negative correlation between self-esteem and body image dissatisfaction [11-13].

Self-esteem is a topic, extensively investigated by the researchers of personality psychology. Actually, it points to a person's attitude towards oneself or to the evaluation of oneself which may be positive or negative [14]. Low self-esteem means that a person suffers from poor self-worth. Studies also show that one-third to one-fourth of self-esteem relates to the feeling that a person has about his/her own physique. If an individual dislikes his/her body, he/she could hardly like the person residing there either [15]. Furnham, Badmin and Sneade [16] identified low self-esteem as a risk factor for body image dissatisfaction and hold that raising self-esteem could diminish body image dissatisfaction. In general, low self-esteem correlates with several mental outcomes like poor body image and body image dissatisfaction [17-19], motivation for weight-loss $[20,21]$ and concern for weight and body shape among university students [22, 23].

From the factors that contribute to body dissatisfaction, the most influential is internalization of societal ideals of attractiveness $[24,25]$. Internalization is a process wherein the standards of a society on a variety of issues like body shape, are adopted as personal codes, e.g. thin-ideal for women or hyper-muscularity for men [26, 27]. If not impossible, it is difficult for most women, to achieve the thin-ideal. As a re- 
sult, once those buying into thin-ideal fail to make themselves over in the image of models, they experience negative feelings about their figure [28].

There are several prevailing postulates that establish a causal relationship between internalization and concerns about body image as well as related disorders. For instance, three sociocultural approaches to eating pathology, i.e. Stice's dual-pathway model, the tripartite influence model of Thompson et al, plus the objectification theory, all suggest that internalization have a direct impact on the construct of body image [29-32]. Furthermore, two decades of experimental and observational study, endorses the idea that internalization plays the key role in the construction of women's body image $[24,25]$.

Another formative factor that contributes to body dissatisfaction is social comparison [33]. Social comparison is a process in which, an individual thinks of his/herself in comparison to others in order to evaluate their own opinions, abilities and social status [34]. According to the social comparison theory, people are more likely to choose target comparison that is similar to themselves as for physical and social attributes. Hence, the target may come from peer groups, family or friends. This process is true about body image too. In fact, social comparison and cultural standards are scales that a person evaluates themselves thereby. Meta analyses have revealed that when women compare themselves with thinner females, their body dissatisfaction increases [35, 36]. As women make social comparisons, they certainly compare their appearances together. These comparisons almost revolve around weight, size, body shape, lower torso or overall physical attractiveness more often. Generally, such studies indicate that appearance-related comparisons have a negative effect on body satisfaction [34].

The present research aimed to study the correlation between body image dissatisfaction and the variables of self-esteem, thin-ideal internalization and appearance-related social comparison as psychological and psychosocial factors respectively. Meanwhile, analyses were done to determine the percentage each variable could explain about body image dissatisfaction.

\section{Methods}

This research falls into a correlational study design. Statistical universe comprised the entire female students of highschools scattered throughout Tehran in the academic year of 2014-2015. The sample population consisted of 477 highschool students who were selected by the Multi-stage Cluster Sampling method. On this account, Tehran was divided into five clusters; then, three sampling units of districts ( $t$ from the northern part, 18 from the southern part, 6 from the central part, 8 from the eastern part and 9 from the western part of Tehran), girls' high schools and classes were randomly selected in stages, so as to recruit the sample population. Required permission was obtained from the Research Division and Committee of Ethics of the Shahid Beheshti University as well as the Ministry of Education. Following the permission, researchers went to the selected high-schools and distributed the questionnaires among the students with prior consent of relevant authorities, viz. high-school principals and teachers. Instruments that were employed in order to collect data are mentioned below. The collected data were analyzed using measures of descriptive statistics (mean and standard deviation) along with techniques of inferential statistics (Pearson's correlation coefficient and stepwise regression) by SPSS version 18 .

2.1. Sociocultural Attitudes toward Appearance Questionnaire-4 (SATAQ-4)

This is an inventory including 22 items which measure the impact of sociocultural dispositions on appearance ideals. It includes 5 subscales which are: the subscale of Internalization of Thin/Low Body Fat which came into use in order to evaluate the variable of thin- ideal internalization in the sample population. The subscale consisted of 5 items in a format of five-level Likert-type rating, from definitely disagree [1] to definitely agree [5]. The subscale was first translated into Persian and then rendered back into English. After on three experts were asked to evaluate the version which had been rendered into original language. After the experts' assessment, researchers carried out a pilot study for determining the validity of the subscale. Cronbach's alpha thereof was estimated to be 0.85 in this study. It is necessary to explain that a considerable body of experimental evidence has confirmed the technical aspects of this subscale [41, 42].

2.2. Multidimensional Body-Self Relations Questionnaire (MBSRQ)

This is an inventory consisting of 46 items which are categorized into 6 subscales. Among those categories, the subscale of Appearance Evaluation was employed to assess body dissatisfaction. This subscale is actually comprised of 7 items in a five-level Likert-type rating scale, from definitely disagree [1] to definitely agree [5]. The mean scores which were achieved by respondents interpreted in the same way that Poloskov and Tracey [43] did in their study. It is said that, the more respondents score in the questionnaire, the greater body dissatisfaction. Besides, Rahati [44] through her research evaluated the validity and reliability of the MBSRQ. The results of evaluation confirmed the validity and reliability of the questionnaire to a great extent. Cronbach's alpha of the subscale was calculated to be 0.71 in this study. Item 1 was dismissed thanks to some cultural constraints.

\subsection{Physical Appearance Comparison Scale}

This questionnaire is a five item Likert-type scale instrument that has an acceptable reliability and validity for body image assessment [37]. This scale assesses the tendency of one's body comparison with others. Answers were scored from never (0) to always [5]. The internal consistency was assessed by the Cronbach's alpha coefficient with an alpha level of 0.84. In an item-scale correlation, we realized that the exclusion of either of the items $1,2,3$, or 5 would reduce the alpha level. However, the exclusion of item 4 resulted in an increase 
from 0.59 to 0.75 . In addition, the correlation between item 4 and the scale (after correction for overlapping) was not significate. Therefore, it seemed that item 4 could be excluded. For final checking, factor analysis was done and results showed that item 4 should be put in a separate category. Such results were achieved in other researches as well [38, 39]. Therefore, final analysis of PACS was done by 4 items $(1,2$, 3 , and 5) and it was considered as PACS4. The validity of this questionnaire was acceptable in Persian.

\subsection{Rosenberg Self-Esteem Scale}

To evaluate self-esteem, the Rosenberg Self-Esteem Scale (RSES) was applied. This questionnaire includes ten items of global statements and is scored from 1 (strongly disagree) to 4 (strongly agree). Negative items are scored negatively. Psychometric properties of this questionnaire were acceptable in Persian [40]. Cronbach's alpha thereof was estimated to be 0.8 in this study.

\section{Results}

Table 1 indicates the frequency distribution of respondents in terms of districts and educational grades. Table 2 shows the descriptive measures used for analyzing data. As this table shows, the mean scores of predictive variables of self-esteem, thin- ideal internalization and appearance-related social comparison are $3.4,1.99$ and 2.88 respectively. The mean score of body dissatisfaction as an independent variable came to 2.2 as well. The results of the correlation matrix suggests that the relations between body dissatisfaction and the variables of thin-ideal internalization $(\mathrm{p}<0.001)$ and appearance-related social comparison $(\mathrm{p}<0.000)$ were significant in a positive direction. The correlation between body dissatisfaction and self-esteem $(\mathrm{p}<0.000)$ was also significant, but in a negative direction (Table 3 ).

To measure the percentage that each variable could explain about the variance of body dissatisfaction, the stepwise regression method was used. Findings indicated that the most efficient variable in predicting body dissatisfaction was selfesteem. The variables of thin- ideal internalization and appearance-related social comparison was excluded from the regression equation. According to the results, the observed $F$ was also significant $(\mathrm{p}<0.000)$ and the variable of self-esteem could account for the variance of body dissatisfaction up to 19\% (Table 4).

\section{Discussion}

Findings of the present study has demonstrated that self-esteem significantly correlates with body dissatisfaction $(\mathrm{p}<$ 0.000 ), but in a negative direction. In fact, these two variables had an inverse relationship which is consistent with the results of Richardson, Paxston and Thomson [45]. The findings of the present research also correspond with the results of studies by Gleason et al, [18], Lowry et al, [46] as well as Furnham, Badmin and Sneade [16].

Table 1. Frequency distribution in terms of districts and education levels

\begin{tabular}{ccccc}
\hline School & District & Quantity & Educational grade & Quantity \\
\hline Public & 1 & 108 & First grade & 246 \\
& 6 & 73 & & 135 \\
& 8 & 100 & Second grade & \\
& 9 & 101 & Third grade & 96 \\
\hline
\end{tabular}

As table 1 sets out, 246 students were in first grade, 135 students were in second grade, 96 students were in third grade

Table 2. Mean and standard deviation of the research variables

\begin{tabular}{lll}
\hline Variable & Mean & Standard deviation \\
\hline Thin- ideal internalization & 3.4 & 1.13 \\
Appearance-related social comparison & 2.88 & 1.17 \\
Self-esteem & 1.99 & 0.54 \\
Body dissatisfaction & 2.2 & 0.78 \\
\hline
\end{tabular}

As table 2 sets out, the mean scores of the predictive variables of self-esteem, thin- ideal internalization and appearance-related social comparison are 3.4, 1.99 and 2.88 respectively. The mean score of body dissatisfaction as an independent variable came to 2.2 as well

Table 3. Correlation matrix of body dissatisfaction with variables of thin- ideal internalization, appearance-related social comparison and self-esteem

\begin{tabular}{ccc}
\hline Variable & Body dissatisfaction & Significance level \\
\hline Thin- ideal internalization & $0.15^{* *}$ & 0.001 \\
Appearance-related social comparison & $0.18^{* *}$ & 0.000 \\
Self-esteem & $-0.44^{* *}$ & 0.000 \\
\hline${ }^{*} \mathrm{P}<0.05 \quad{ }^{* *} \mathrm{p}<0.01$ & &
\end{tabular}

As table 3 sets out, the relations between body dissatisfaction and the thin- ideal internalization ( $\mathrm{p}<0.001)$ and the appearance-related social comparison ( $\mathrm{p}<$ 0.000 ) variables were significant in a positive direction. The correlation between body dissatisfaction and self-esteem ( $\mathrm{p}<0.000)$ was also significant, but in a negative direction.

Table 4. Summary of the results of stepwise regression for the prediction of body dissatisfaction

\begin{tabular}{cccccc}
\hline Variable & $\mathbf{R}$ & $\mathbf{R 2}$ & $\mathbf{F}(\mathbf{p})$ & $\boldsymbol{\beta}$ & $\mathbf{t}(\mathbf{p})$ \\
\hline Self-esteem & 0.44 & 0.19 & $112,747(0.000)$ & -0.44 & $-10.62(0.000)$ \\
\hline
\end{tabular}

As table 4sets out, the observed F was significant $(\mathrm{p}<0.000)$ and the self-esteem variable could account for the variance of body dissatisfaction up to $19 \%$. 
To explain these findings, it is probable that adolescents with poor self-esteem on one hand and high level of self-consciousness on the other, certainly incline towards self-criticism and consequently experience greater body dissatisfaction and further eating disturbances [47]. In addition, the results showed that appearance-related social comparison had a positive correlation $(\mathrm{p}<0.000)$ with body dissatisfaction. In other words, if appearance-related social comparison increases, body dissatisfaction will grow as a result. This conclusion matches up with the findings of Bailey and Ricciardelli [35] as well as Myers and crowther [36]. Possible explanation for such a relationship could be that social comparison and attention to cultural standards emerge as measures whereby people evaluate their bodies. There is substantial evidence showing that pressure on women to achieve a thin-ideal body, mostly results from comparisons they make between their figure and the ideal female body of their perception [34]. Generally speaking, an ideal female body which the media promote is thinner than the average woman. This is why comparisons may lead to a sense of guilt accompanied by body dissatisfaction. [48-50]. Moreover, the results suggested that thin- ideal internalization had a significant correlation $(\mathrm{p}<0.001)$ with body dissatisfaction in a positive direction. It means when thin-as-ideal is more internalized by women, the level of body dissatisfaction will increase. This conclusion is consistent with the findings of Vartanian [28] as well as Nouri, Hill and Orrell-Valente [51]. It is also compatible with the findings of Cafri et al, [24] and Stice [52]. A plausible reason for this conclusion is because thin- ideal internalization makes people set high standards which are unlikely to meet. As a result, differences between the current figure and the ideal body shape leads to people's body dissatisfaction as well as other mental disorders.

According to the results of stepwise regression, self-esteem is the most efficient variable in predicting body dissatisfaction. In fact, this is the advantage that distinguishes the present study from the others mentioned above. Self-esteem plays a supporting role in addressing challenges of life and promotes people's resilience in the face of difficulties. A human beings, whether a child, an adolescent or a mature adult who has a sense of self-assurance, completely believe in their abilities and also know that he/she is agreeable. Additionally, a selfassured person expresses optimism and does not yield to social standards which are irrational. It is worth saying that in the vocabulary of self-confident people, success does not essentially mean an ideal appearance [15].

\section{Conclusion}

Among the advantages of this study, giving importance to personal differences can be mentioned. In fact, contrasts between people that predispose them to body dissatisfaction, are now seen as measures thereby alleviating symptoms of eating disorders. Personal differences not only broaden our knowledge of body image as well as eating disturbances, but also have implications for assessment, prevention, intervention or any other clinical purposes. For instance, Stice and Shaw [53] came to know that when targeting preventive measures on vulnerable or at-high-risk groups, it brought them with more results of interest. Thus, identification of risk factors through differences can be useful in selecting individuals who benefit from preventive measures to maximum extents. From a preventive point of view, these risk factors could be beneficial to reducing the symptoms of body image disturbances or eating disorders.

One of the constraints that was faced while conducting this study was the sample population. In this study, the entire respondents were female high-school students. For this reason, when generalizing the results of the current study to other societal sections, it is best to err on the side of caution. It is also recommended to conduct further research on a diverse sample population to make firmer decisions.

Another constraint was the correlational study design which thrived in the current study. On this account, causal inferences cannot be drawn. However, future studies could take notice of this issue and experiments can be done to evaluate the efficacy of predictive variables in reducing body dissatisfaction. Finally, it is recommended doing further research considering other social and personal variables to cover different aspects of discontent of body image.

\section{Acknowledgements}

Hereby, we thank all the authorities from the Ministry of Education as well as the selected high schools across Tehran who helped us to carry out this study.

\section{Authors' Contribution}

The authors were involved in the study design, data collection, interpretation of the results, and the preparation of the manuscript.

\section{Funding/Support}

This study was support by the Shahid Beheshti University of Medical Sciences.

\section{Financial Disclosure}

Not declared.

\section{Refrences}

1. Borzekoeski DL, Bayer AM. Body Image and Media Use among Adolescents. Adolescent Medicine Clinics. 2005;16(2):289-302.

2. Cash T F, Melnyk SE, Hrabosky JI. The Assessment of Body Image Investment: An Extensive Revision of the Appe Arance Schemas Inventory. International J Eating Disorders. 2004;35:305-16.

3. Thompson JK, Van Den Berg P, Rohring M, Guarda AS, HeinbergLJ. The Sociocultural Attitudes towards Appearance Scale-3(SATAQ-3): Development and Validation, IJED. 2004;35(3):293-304.

4. Levine MP, Smolak L. Body image development in adolescents. In Cash TF, Pruzinsky T, editors. Body image: A handbook of theory, research, and clinical practice. New York: Guilford Press; 2004. P. 482.

5. LePage ML, Crowther JH. The Effects of Exercise on Body Satisfaction and Affect. Body Image. 2010;7:124-30.

6. Sujoldzic A, Lucica AD. A cross-cultural study of adolescents-BMI body image and psychological well-being. Coll Antropol. 
2007;31(1):123-30

7. Kornblau IS, Pearson HC, Breitkopf CR. Demographic, behavioral and physical correlates of body esteem among low - income female adolescents. J Adolesc Health. 2007;41:566-70.

8. Annis, N.M.Cash, T.F.Hrabosky, J.I. Body image and psychosocial differences among stable average-weight, currently overweight, and formerly overweight women: the role of stigmatizing experiences. Body Image: IJR. 2004;1:155-67.

9. Basak Nejad S, Ghafari M. Relation between body dysmorphic concern and psychological disorders in students of university. J Behavior Sci Res Center. 2007;1(2):179-87. Persian

10. Shamsaddin Saeed N, Aziz-zade FM, Mohammad Alizadeh S, Haghdoost AA, Gross B. Relationship of body image and eating disorders. J Nurs Res. 2009;4(15):33-43. Persian

11. Grogan, s. Body image: understanding body dissatisfaction in men women, and children. New York: routledge; 2008.

12. Clay D, Vignoles VL, Dittmar H. Body image and self-esteem among adolescent girls: Testing the influence of sociocultural factors. Journal of Research on Adolescence. 2005; 15 (4): 451-77.

13. Thompson JK, Smolak L. Body image, eating disorders, and obesity in youth: Assessment, prevention, and treatment. Washington DC: American Psychological Association; 2001

14. Kinnunen ML, Feldt T, Kinnunen U, Pulkkinen L. Self- Esteem: An Antecendent or a Consequence of Social Support and Psychosomatic Symptoms? Cross-lagged Associations in Adulthood, J Res Pers. 2008:42:333-47.

15. Cash FT. The Body Image Workbook. New York: Fine Communications; 1998.

16. Furnham A, Badmin, N, Sneade I. Body Image Dissatisfaction: Gender Differences in Eating Attitudes, Self-esteem, and Reasons for Exercise. Journal of Psychology. 2002;136:581-96.

17. Abell SC, Richards MH. The Relationship between Body Shape Satisfaction and Self Esteem: An Investigation of Gender and Class Differences. J Youth Adolesc. 1996; 25: 691-703.

18. Gleason JH, Alexander AM., Somers CL. Later Adolescents' Reactions to Three Types of Childhood Teasing: Relation with Selfesteem and Body Image, Social Behavior and Personality. 2002;28:472-80.

19. Lowery SE, Kurpius SER, Befort C, Blanks EH, Sollenberger S Nicpon MF, et al. Body Image, Self-esteem, and Health Behaviors among Male and Female First Year College Students, Journal of College Student Development. 2005; 46: 612-23.

20. Milligan B, Pritchard ME. The relationship between gender, Type of sport, self-esteem and eating disordered behaviors in Division I athletes. Athletic Insight. 2006; 8: 9-43.

21. Shea M, Pritchard ME. Is self-esteem the primary predictor of disordered eating? Personality and Individual Differences. 2007;42:152737.

22. Delinsky SS, Wilson GT. Weight gain, dietary restraint, and disordered eating in the freshman year of college. Eating Behaviors. 2008;9:82-90.

23. Pritchard M. Does self esteem moderate the relation between gender and weight ore occupation in undergraduates? Personality and Individual Differences. 2010;48:224-27.

24. Cafri G, Yamamiya Y, Brannick M, Thompson JK. The influence of sociocultural factors on body image: Ameta-analysis. Clinical Psychology: Science and Practice. 2005;12:421-33.

25. Thompson JK, Stice E. Thin-ideal internalization: Mounting evidence for a new risk factor for body-image disturbance and eating pathology. Current Directions in Psychological Science. 2001;10:181-3.

26. Jones DC. Body image among adolescent girls and boys: A longitudinal study. Developmental Psychology. 2004;40:823-35.

27. Thompson JK, Heinberg LJ, Altabe M, Tantleff-Dunn S. Exacting beauty: Theory, assessment, and treatment of body image disturbance. Washington, DC: American PsychologicalAssociation; 1999.

28-Vartanian LR. When the body defines these lf: Self-concept clarity, internalization, and body image. Journal of Social and Clinical Psychology. 2009;28:94-26.

29. Stice E, Schupak-Neuberg E, Shaw HE, Stein RI. Relation of media exposure to eating disorder symptomatology: An examination of media ting mechanisms. Journal of Abnormal Psychology. 1994;103:836-40.

30. Thompson JK, Heinberg LJ, Altabe M, Tantleff-Dunn S. Exacting beauty: Theory, assessment, and treatment of body image disturbance. Washington, DC: American Psychological Association; 1999.

31. Fredrickson BL, Roberts T. Objectification theory: Toward understanding women's lived experiences and mental health risks. Psychology of Women Quarterly. 1997;21:173-6.

32. Moradi B, Huang YP. Objectification theory and psychology of women: A decade of advances and future directions. Psychology of Women Quarterly. 2008;32:377-98.
33. Leahey TM, Crowther JH, Mickelson KD. The frequency, nature, and effects of naturally occurring appearance-focused social comparisons. Behavior Therapy. 2007; 38: 132-43.

34. Varga H. Social comparison and body image in none or infrequent exercisers. [Dissertation]: Brock University; 2009.

35. Bailey SD, Ricciardelli LA. Social comparisons, appearance related comments, contingent self-esteem and their relationships with body dissatisfaction and eating disturbance among women. Eating Behaviors. 2010;11:107-12

36. Myers TA, Crowther JH. Sociocultural pressures, thin-ideal internalization, self objectivation, and body dissatisfaction: could feminist beliefs be a moderating factor? Body image. 2007;4:296-98.

37. Thompson JK, Heinberg L, Tantleff S. The Physical Appearance Comparison Scale (PACS). Behav Ther. 1991;14:174.

38. Keery H, Kerri B, Van den Berg P, Thompson JK. The impact of appearance-related teasing by family members. J Adolesc Health. 2005;37(2):120-27.

39-Jackson T, Chen H. Sociocultural Predictors of Physical Appearance Concerns among Adolescent Girls and Young Women from China. Sex Roles. 2007;58(5-6):402-11.

40. Shapurian R, Hojat M, Nayerahmadi H. Psychometric characteristic and dimensionality of a Persian version of the Rosenberg Self-Esteem Scale. Percept Mot Skills. 1987;65(1):27-34.

41. Schaefer LM, Burke NL, Thompson JK, Dedrick RF, Heinberg LJ, Calogero RM, et al. Development and Validation of the Sociocultural Attitudes towards Appearance Questionnaire-4 (SATAQ-4). Psychol Assess. 2014; 170-5

42. Llorente E, Gleaves DH, Warren CS, Pérez-de-Eulate L, Rakhkovskaya $L$. Translation and validation of a spanish version of the sociocultural attitudes towards appearance questionnaire-4 (SATAQ-4). Int J Eat Disord. 2015;48(2):170-5.

43. Poloskov E, Tracey GT. Internalization of U.S. female beauty standards as a mediator of the relationship between Mexican American women's acculturation and body dissatisfaction. Body Image. 2013;10:501-8

44. Rahati A. Evolutionary Study of body image and its relationship with self-esteem based on comparison between adolescent, middle age and old people [Dissertation]: Shahed University; 2004. Persian

45. Richardson SM, Paxston SJ, Thomson JS. Is Body Think an Efficacious Body Image and Self-esteem Program? A controlled Evaluation with Adolescents. Body Image. 2009;6:75-82.

46-Lowery SE, Kurpius SER, Befort C, Blanks EH, Sollenberger S, Nicpon MF, et al. Body Image, Self-esteem, and Health Behaviors among Male and Female First Year College Students, JCSD. 2005;46:612-23.

47. Courtney EA, Gamboz J, Johnson JG. Problematic eating behaviors in adolescents with low self-esteem and elevated depressive symptoms. Eat Behav 2008;9(4):408-14.

48. Van den Berg P, Thompson JK, Obremski-Brandon K, Coovert M. The tripartite influence model of body image and eating disturbance: A covariance structure modeling investigation testing the mediating role of appearance comparison. J Psychosomatic Res. 2002;53:100720.

49. Tiggemann, M. Media influences on body image development. In T. F. Cash \& T. Pruzinsky (Eds.), Body image: A handbook of theory, research and clinical practice. New York: Guilford Press; 2002, p. 918

50-Tiggemann M, McGill B. The role of social comparison in the effect of magazine advertisements on women's mood and body dissatisfaction. JSCP. 2004;23:23-44.

51. Nouri M, Hill LG, OrrellValente JK. Media exposure, internalization of the thin ideal, and body dissatisfaction: Comparing Asian American and European American college females. Body Image. 2011;8:366-72.

52. Stice E. Risk and maintenance factors for eating pathology: A metaanalytic review. Psychological Bulletin. 2002;128:825-48.

53. Stice E, Shaw H. Eating disorder prevention programs a Meta analytic review. Psychological Bulletin. 2004;130:206-27. 